\title{
Clinical Radiology for Paediatricians
}

"Clinical Radiology for Paediatricians" by Dr. Binit Sureka and Dr. Aliza Mittal (ISBN 9788184451771) published in 2015 by Peepee Publishers and Distributors (P) Ltd is a comprehensive book on radiological findings in paediatric clinical conditions. The book with 206 pages is primarily targeted to medical students, interns, general practitioners and paediatricians. The book presents radiological findings of paediatric clinical conditions along with clinical correlation and is focused on preparation for various clinical entrance examinations and everyday clinical practice. Combination of a paediatrician and a radiologist as authors in this book has added additional benefit to the reader for correlation between radiological and clinical signs.

The book includes wide range of clinical conditions in children which are organized according to different anatomical structures. Cases are grouped under chest, abdomen, central nervous system etc making the book easier to read. It covers most of the commonly encountered clinical conditions in children. Radiological findings are explained along with the clinical signs and symptoms. Readers can easily access clinical information while dealing with a particular radiograph. Reading the book helps readers to correlate and to reach a correct diagnosis. The book includes photos of X-ray, MRI, CT and ultrasound giving a wider understanding of various clinical conditions to the reader. Description of findings of a particular clinical condition in X-ray, MRI, CT and sometimes in ultrasound gives the holistic understanding of the disease. Since the book is also targeted to the beginners in clinical medicine, if some normal radiographs were included, it would have helped to understand the normal anatomy which is very important for the correct interpretation of pathological findings in the radiographs.

The book also includes clinical signs, differential diagnosis and radiological findings giving a complete picture of a clinical condition. This increases better understanding of the pathology. If authors had included the pathophysiology for the radiological findings it would have increased the value of the book to the reader. To further improve the quality of book the authors could have mentioned the best diagnostic test for the given clinical condition which would have helped to make the book more holistic in its clinical approach.

The inclusion of differential diagnosis helps reader to better understand the various clinical conditions. Many clinical conditions are listed for some radiological findings where as they are missing in some.

\author{
Authors: Dr. Binit Sureka \\ Dr. Aliza Mittal
}

\section{Edition:}

Publisher: Peepee Publishers and

Distributors

Pages: 206

ISBN: 9787184451771

This work is licensed under a Creative Commons Attribution 3.0 License.

\section{(c) (i)}

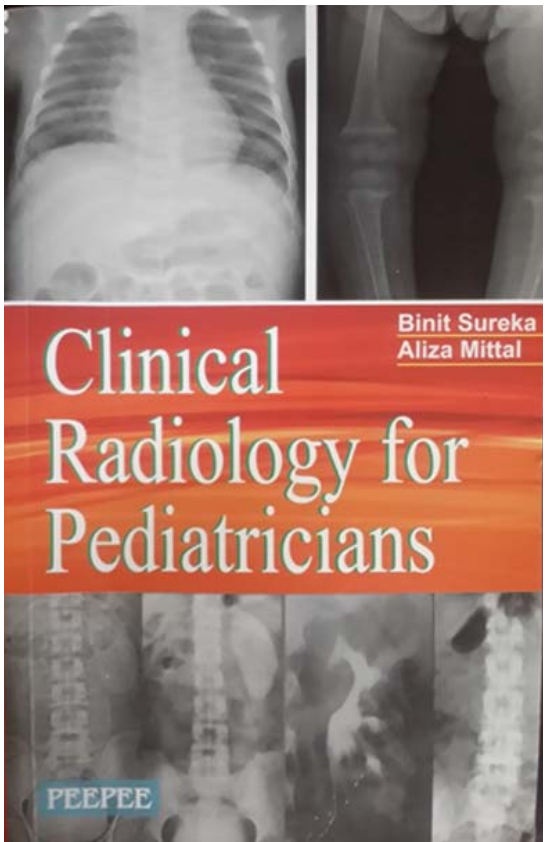


The last chapter of the book included as "brainstorming chapter" is very useful to the beginners and for readers appearing for the entrance exams. It includes radiographic photos of various clinical conditions diagnosis of which are presented at the different section of the book. This helps reader to practice what is learnt previously.

The quality of print in the book is very good. The book is printed in a portable format. It can be kept in the pocket of the lab coat when in the clinics. This has made this book more users friendly. The authors have cited references in the initial pages of the book.

In conclusion, the book is very comprehensive and useful to the beginners of clinical practice whether general or paediatrics. Authors' effort to correlate the clinical findings and the radiographic findings is very helpful to understand the correct diagnosis. However, improving several dimensions like use of better quality photos of radiographs, labelling of radiographs, inclusion of normal radiographs and inclusion of explanation for the radiological findings along with appropriate referencing would have made the book better and more users friendly. Despite the areas for improvement the book is worth reading especially for doctors in early stage of clinical carrier.

Dr. Nirjala Aryal Assistant Professor Nepalese Army Institute of Health Sciences

Shree Birendra Hospital (Chhauni) Kathmandu, Nepal

Dr. Arun Neopane Associate Professor Nepalese Army Institute of Health Sciences

Shree Birendra Hospital (Chhauni), Kathmandu, Nepal 